\title{
Chemoradiotherapy versus surgery followed by postoperative radiotherapy in tonsil cancer: Korean Radiation Oncology Group (KROG) study
}

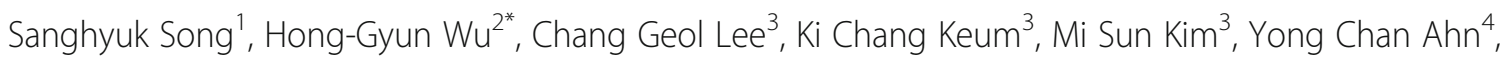
Dongryul Oh ${ }^{4}$, Hyo Jung Park', Sang-Wook Lee ${ }^{5}$, Geumju Park ${ }^{5}$, Sung Ho Moon ${ }^{6}$, Kwan Ho Cho ${ }^{6}$, Yeon-Sil Kim', Yongkyun Won ${ }^{7}$, Young-Taek $\mathrm{Oh}^{8}$, Won-Taek Kim ${ }^{9}$ and Jae-Uk Jeong ${ }^{10}$

\begin{abstract}
Background: Treatment of tonsil cancer, a subset of oropahryngeal cancer, varies between surgery and radiotherapy. Well-designed studies in tonsil cancer have been rare and it is still controversial which treatment is optimal. This study aimed to assess the outcome and failure patterns in tonsil cancer patients treated with either approaches.

Methods: We retrospectively reviewed medical records of 586 patients with tonsil cancer, treated between 1998 and 2010 at 16 hospitals in Korea. Two hundred and one patients received radiotherapy and chemotherapy (CRT), while 385 patients received surgery followed by radiotherapy and/or chemotherapy (SRT). Compared with the SRT group, patients receiving CRT were older, with more advanced T stage and received higher radiotherapy dose given by intensity modulation techniques. Overall survival (OS), disease-free survival (DFS), locoregional recurrence-free survival (LRRFS), distant metastasis-free survival (DMFS), and clinicopathologic factors were analyzed.
\end{abstract}

Results: At follow-up, the 5-year OS, DFS, LRRFS and DMFS rates in the CRT group were 82, 78, 89, and 94\%, respectively, and in the SRT group were $81,73,87$, and $89 \%$, respectively. Old age, current smoking, poor performance status, advanced T stage, nodal involvement, and induction chemotherapy were associated with poor OS. Induction chemotherapy had a negative prognostic impact on OS in both treatment groups ( $p=0.001$ and $p=0.033$ in the CRT and SRT groups, respectively).

Conclusions: In our multicenter, retrospective study of tonsil cancer patients, the combined use of radiotherapy and chemotherapy resulted in comparable oncologic outcome to surgery followed by postoperative radiotherapy, despite higher-risk patients having been treated with the definitive radiotherapy. Induction chemotherapy approaches combined with either surgery or definitive radiotherapy were associated with unfavorable outcomes.

Keywords: Tonsil cancer, Chemoradiotherapy, Surgery, Adjuvant radiotherapy, Induction chemotherapy

\footnotetext{
*Correspondence: wuhg@snu.ac.kr

${ }^{2}$ Department of Radiation Oncology, Seoul National University College of

Medicine, 101 Daehangno, Jongno-gu, Seoul 110-744, Republic of Korea

Full list of author information is available at the end of the article
} 


\section{Background}

The tonsils, a subsite of the oropharynx, are the most common site of oropharyngeal neoplasm [1]. The incidence of tonsil cancer is increasing [2,3]. Odynophagia, dysphagia, otalgia and asymptomatic mass is common presentations. Histologically, squamous cell carcinoma is most commonly observed in tonsil cancer. Regional nodal metastases are frequent in more than half of patients, while contralateral nodal diseases are found in more than one fifth of patients with tonsil cancer [4]. Management of tonsil cancer is limited to either surgery or radiotherapy, yet there is a scarcity of randomized prospective trials comparing these treatment options. However, several retrospective studies published similar oncologic outcomes with both modalities [5-7]. Therefore, current guidelines recommend both strategies based on such findings [8].

In recent decades, breakthroughs in the field have included the introduction of chemotherapy, resulting in improved survival rates after definitive radiotherapy and postoperative radiotherapy [9, 10]. Furthermore, randomized clinical trial data showed that more than half of oropharyngeal cancers were human papillomavirus (HPV) positive and responded well to definitive radiotherapy [11]. The incidence of HPV positive tumors is continuously increasing [12]. In the era of chemotherapy and endemic HPV, comparisons of the efficacy between treatment modalities is still controversial. In the present study, we conducted a large-scale retrospective multicenter study to evaluate the outcome of chemoradiotherapy and surgery followed by postoperative radiotherapy in tonsil cancer patients.

\section{Methods}

A total of 620 tonsil cancer patients who were treated with radiotherapy between 1998 and 2010 were identified in 16 institutions in Korea. Of these, we analyzed data from 586 patients who were treated with definitive radiotherapy with chemotherapy (CRT; 201 patients) or surgery followed by radiotherapy and/or chemotherapy (SRT; 385 patients). All institutional review boards of participating hospitals approved the collection of these data. The need for consent had been waived by the institutional review boards. Patient demographics, performance status, smoking history, imaging study, stage, pathology, type of surgery, radio- and chemotherapeutic information, and follow-up results were compiled.

The median age at diagnosis was 56 (range, 26-89) and patients were predominantly male (89\%). The performance status of most patients was Eastern Cooperative Oncology Group (ECOG) grade 0-1 (94\%). More than half of the patients (52\%) had a history of smoking. Computed tomography (CT) scans of the neck were performed at diagnosis in $91 \%$ of individuals; positron emission tomography (PET) or CT scans were taken in $69 \%$ of patients, while magnetic resonance imaging of the oropharynx and neck was performed in $48 \%$.

Patient characteristics according to the two treatment groups are summarized in Table 1 . Younger patients and those with early $\mathrm{T}$ stage were more likely to receive surgery ( $p=0.041$ and 0.002 , respectively). Unknown histologic differentiation was less frequent in the SRT group. Chemotherapy and intensity modulated radiotherapy (IMRT) were more commonly used in the CRT group ( $p<0.001$ and 0.014 , respectively). Radiotherapy dose was also higher in the CRT group than in those receiving SRT $(p<0.001)$.

Overall survival (OS) was defined as the time from the date of treatment initiation to either death or last follow-up. Disease-free survival (DFS) was defined as the time from treatment initiation to recurrence, death, or last follow-up. Locoregional recurrence-free survival (LRRFS) and distant metastasis-free survival (DMFS) were defined as the time from treatment initiation to locoregional/distant recurrence or last follow-up, respectively. Univariate and multivariate analyses were performed using the log rank test and Cox-proportional hazard regression model, respectively.

\section{Results}

With a median follow-up duration of 54 months (range, 2-176 months), 67 (11\%) patients demonstrated locoregional recurrence, while 50 (9\%) patients failed with distant metastases. The 5-year OS, DFS, LRRFS, and DMFS rates of the cohort as a whole were 81, 75, 87, and $91 \%$, respectively. When the data from the CRT and SRT groups were analyzed independently, no significant differences were observed between the two groups. The 5 -year OS rates were 82 and $81 \%(p=0.698)$ in the CRT and SRT groups, respectively; DFS, 78 and $73 \%$ $(p=0.612)$; LRRFS, 89 and $87 \%(p=0.695)$; and DMFS, 94 and $89 \%(p=0.157)$. The survival curves of each group are plotted in Fig. 1.

Older age, current smoking, advanced $\mathrm{T}$ and $\mathrm{N}$ stage, and induction chemotherapy treatment were associated with poor OS in the univariate analysis (Table 2). Furthermore, patients undergoing induction chemotherapy showed inferior survival in both treatment groups (Fig. 2); the 5-year OS rates of patients treated with and without induction chemotherapy were 71 and $83 \%$, respectively $(p<0.001)$. This significant finding was also observed when the treatment groups were analyzed independently; in the CRT group, the 5-year OS rates of patients with or without induction chemotherapy were 70 and $84 \%(p=0.001)$, respectively, and $72 \%$ vs $82 \%$ in the SRT group ( $p=0.033)$.

The multivariate analysis (Table 3 ) also indicated that induction chemotherapy was a risk factor for poor OS 
Table 1 Patient Characteristics

\begin{tabular}{|c|c|c|c|c|c|c|c|}
\hline \multirow[t]{2}{*}{ Characteristic } & \multicolumn{7}{|c|}{ Number of patients (\%) } \\
\hline & \multicolumn{2}{|c|}{ All $(n=586)$} & \multicolumn{2}{|c|}{ CRT $(n=201)$} & \multicolumn{2}{|c|}{$\mathrm{SRT}(n=385)$} & $\frac{p \text {-value }}{0.913}$ \\
\hline Male & 523 & (89) & 179 & (89) & 344 & (89) & \\
\hline Female & 63 & (11) & 22 & (11) & 41 & (11) & \\
\hline Age (years) & & & & & & & 0.041 \\
\hline$<60$ & 395 & $(67)$ & 125 & $(62)$ & 270 & (70) & \\
\hline$\geq 60$ & 189 & (32) & 76 & (38) & 113 & (29) & \\
\hline Unknown & 2 & (0) & 0 & (0) & 2 & (1) & \\
\hline Smoker & & & & & & & 0.673 \\
\hline Never smoker & 232 & $(40)$ & 73 & $(36)$ & 159 & $(41)$ & \\
\hline Ex-smoker ${ }^{a}$ & 98 & (17) & 32 & (16) & 66 & (17) & \\
\hline Current smoker & 206 & (35) & 73 & (36) & 133 & (35) & \\
\hline Unknown & 50 & (8) & 23 & $(11)$ & 27 & (7) & \\
\hline Performance & & & & & & & 0.351 \\
\hline ECOG 0 & 197 & (34) & 74 & (37) & 123 & $(32)$ & \\
\hline ECOG 1 & 351 & $(60)$ & 117 & $(58)$ & 234 & $(61)$ & \\
\hline ECOG 2 & 21 & (3) & 5 & (2) & 16 & (4) & \\
\hline Unknown & 17 & (3) & 5 & (2) & 12 & (3) & \\
\hline $\mathrm{PET} / \mathrm{CT}$ & & & & & & & 0.072 \\
\hline No & 182 & (31) & 72 & $(36)$ & 110 & $(29)$ & \\
\hline Yes & 404 & (69) & 129 & (64) & 275 & (71) & \\
\hline Differentiation & & & & & & & $<0.001$ \\
\hline WD & 62 & (11) & 15 & (7) & 47 & $(12)$ & \\
\hline$M D$ & 297 & $(51)$ & 73 & $(36)$ & 224 & $(58)$ & \\
\hline PD & 129 & $(22)$ & 37 & (18) & 92 & (24) & \\
\hline UD & 16 & (3) & 11 & (5) & 5 & (1) & \\
\hline Unknown & 82 & (14) & 65 & $(32)$ & 17 & (4) & \\
\hline T stage & & & & & & & 0.002 \\
\hline $\mathrm{T} 1$ & 134 & (23) & 31 & (15) & 103 & (27) & \\
\hline $\mathrm{T} 2$ & 292 & $(50)$ & 101 & $(50)$ & 191 & $(50)$ & \\
\hline T3 & 74 & (13) & 30 & (15) & 44 & $(11)$ & \\
\hline T4a & 73 & $(12)$ & 30 & (15) & 43 & $(11)$ & \\
\hline $\mathrm{T} 4 \mathrm{~b}$ & 13 & (2) & 9 & (4) & 4 & (1) & \\
\hline N stage & & & & & & & 0.779 \\
\hline No & 73 & $(12)$ & 20 & $(10)$ & 53 & (14) & \\
\hline N1 & 79 & (13) & 28 & (14) & 51 & (13) & \\
\hline $\mathrm{N} 2 \mathrm{a}$ & 45 & (8) & 16 & (8) & 29 & (8) & \\
\hline $\mathrm{N} 2 \mathrm{~b}$ & 307 & $(52)$ & 105 & $(52)$ & 202 & $(52)$ & \\
\hline $\mathrm{N} 2 \mathrm{C}$ & 60 & (10) & 23 & (11) & 37 & (10) & \\
\hline N3 & 22 & (4) & 9 & (4) & 13 & (3) & \\
\hline Stage & & & & & & & 0.092 \\
\hline 1 & 8 & (1) & 2 & (1) & 6 & (2) & \\
\hline$\|$ & 42 & (7) & 23 & (11) & 37 & (10) & \\
\hline
\end{tabular}


Table 1 Patient Characteristics (Continued)

\begin{tabular}{|c|c|c|c|c|c|c|c|}
\hline III & 82 & (14) & 29 & (14) & 53 & (14) & \\
\hline IVA & 419 & $(72)$ & 143 & (71) & 276 & (72) & \\
\hline IVB & 35 & $(6)$ & 18 & (9) & 17 & (4) & \\
\hline Chemotherapy & & & & & & & $<0.001$ \\
\hline Induction & 61 & $(10)$ & 33 & (16) & 28 & (7) & \\
\hline Concurrent & 244 & $(42)$ & 167 & (83) & 77 & (20) & \\
\hline Adjuvant & 13 & (2) & 1 & (1) & 12 & (3) & \\
\hline No & 268 & $(46)$ & 0 & (0) & 268 & (70) & \\
\hline Radiotherapy technique & & & & & & & 0.014 \\
\hline 3D-CRT & 391 & $(67)$ & 121 & $(60)$ & 270 & (70) & \\
\hline IMRT & 194 & (33) & 80 & $(40)$ & 114 & (30) & \\
\hline Unknown & 1 & (0) & 0 & (0) & 1 & (0) & \\
\hline Total dose of radiotherapy & \multicolumn{2}{|c|}{ Median 66} & \multicolumn{2}{|c|}{ Median 70} & \multicolumn{2}{|c|}{ Median 63} & $<0.001$ \\
\hline (Gy) & \multicolumn{2}{|c|}{ (range, 25.2-76) } & \multicolumn{2}{|c|}{ (range, 59.4-76) } & \multicolumn{2}{|c|}{ (range, 25.2-72.6) } & \\
\hline
\end{tabular}

Abbreviations: CRT radiotherapy with chemotherapy, SRT surgery followed by radiotherapy, ECOG Eastern Cooperative Oncology Group, PET/CT positron emission tomography/computed tomography, WD well differentiated, $M D$ moderate differentiation, $P D$ poor differentiation, UD undifferentiated, $3 D-C R T$ three-dimensional conformal radiotherapy, IMRT intensity modulated radiotherapy

${ }^{a}$ An adult who has smoked at least 100 cigarettes in his or her lifetime but who had quit smoking at the time of diagnosis
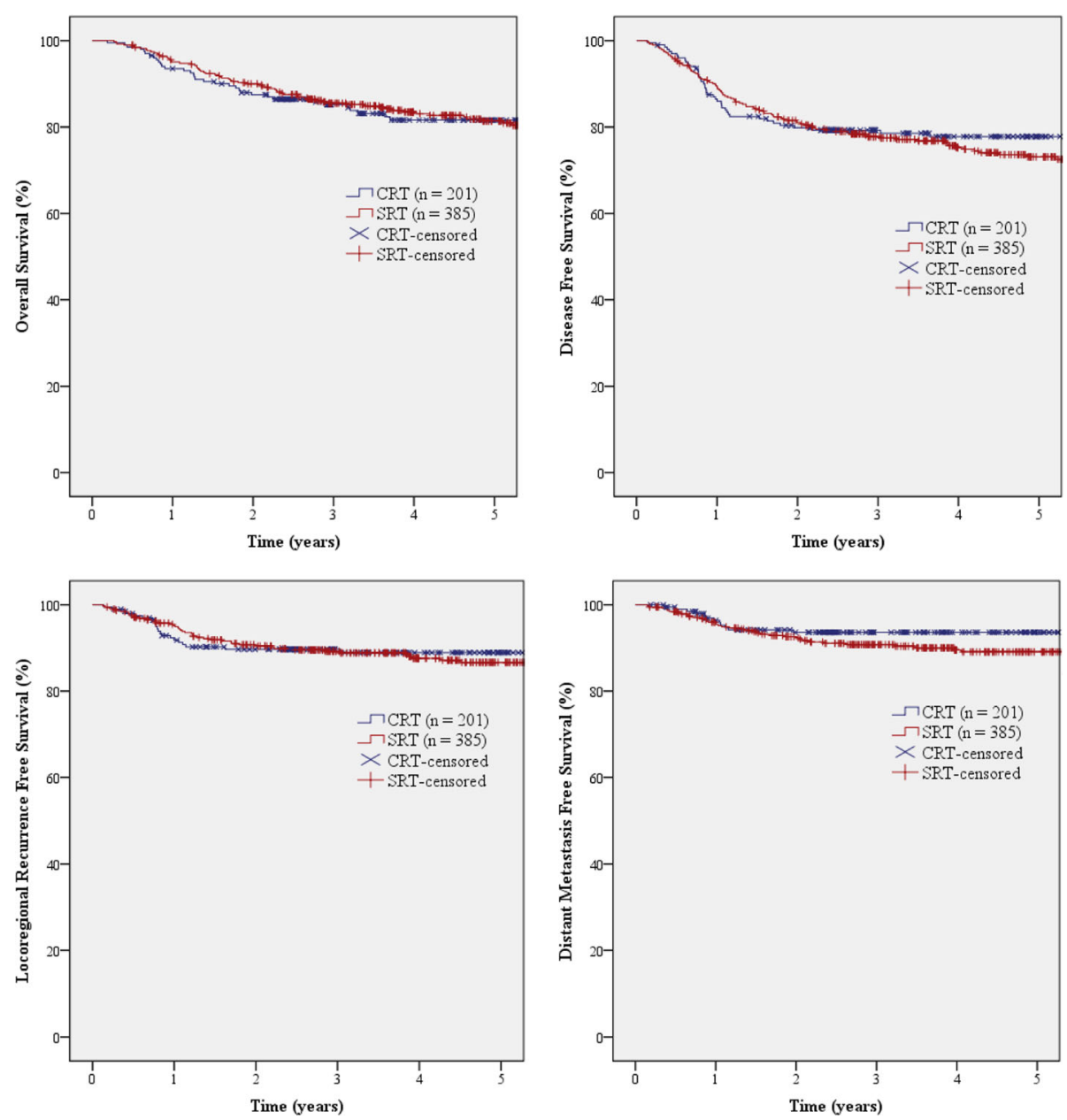

Fig. 1 Overall survival, disease-free survival, locoregional recurrence-free survival, and distant metastasis-free survival according to treatment group 
Table 2 Univariate Analyses

\begin{tabular}{|c|c|c|c|c|c|c|c|c|c|c|c|c|}
\hline \multirow[t]{2}{*}{ Characteristic } & \multicolumn{3}{|l|}{ OS } & \multicolumn{3}{|l|}{ DFS } & \multicolumn{3}{|c|}{ LRRFS } & \multicolumn{3}{|c|}{ DMFS } \\
\hline & No. & $5 Y(\%)$ & $\overline{p \text {-value }}$ & No. & $5 Y(\%)$ & $p$-value & No. & $5 Y(\%)$ & $p$-value & No. & $5 Y(\%)$ & $p$-value \\
\hline \multicolumn{13}{|l|}{ Sex } \\
\hline Male & 523 & 80 & 0.082 & 521 & 73 & 0.037 & 525 & 86 & 0.025 & 522 & 91 & 0.787 \\
\hline Female & 63 & 90 & & 63 & 88 & & 63 & 94 & & 63 & 91 & \\
\hline \multicolumn{13}{|l|}{ Age (years) } \\
\hline$<60$ & 395 & 85 & $<0.001$ & 393 & 80 & $<0.001$ & 395 & 89 & 0.121 & 394 & 92 & 0.026 \\
\hline$\geq 60$ & 189 & 73 & & 189 & 62 & & 189 & 83 & & 189 & 86 & \\
\hline \multicolumn{13}{|l|}{ Smoking history } \\
\hline Never/ex-smoker & 330 & 85 & 0.001 & 329 & 79 & 0.001 & 330 & 90 & 0.005 & 330 & 92 & 0.306 \\
\hline Current smoker & 206 & 76 & & 205 & 67 & & 206 & 82 & & 205 & 89 & \\
\hline \multicolumn{13}{|l|}{ Performance status } \\
\hline ECOG 0 & 197 & 85 & 0.094 & 197 & 80 & 0.027 & 197 & 93 & 0.008 & 197 & 92 & 0.45 \\
\hline ECOG 1-2 & 372 & 79 & & 370 & 72 & & 372 & 85 & & 371 & 90 & \\
\hline \multicolumn{13}{|l|}{$\mathrm{PET} / \mathrm{CT}$} \\
\hline No & 182 & 79 & 0.226 & 181 & 74 & 0.847 & 182 & 88 & 0.669 & 182 & 93 & 0.311 \\
\hline Yes & 404 & 83 & & 403 & 74 & & 404 & 87 & & 403 & 89 & \\
\hline \multicolumn{13}{|l|}{ T stage } \\
\hline $\mathrm{T} 1-\mathrm{T} 2$ & 426 & 87 & $<0.001$ & 425 & 81 & $<0.001$ & 426 & 90 & 0.003 & 425 & 94 & $<0.001$ \\
\hline T3-T4 & 160 & 67 & & 159 & 58 & & 160 & 81 & & 160 & 82 & \\
\hline \multicolumn{13}{|l|}{ N stage } \\
\hline NO-N2b & 504 & 84 & 0.005 & 503 & 78 & $<0.001$ & 504 & 88 & 0.055 & 504 & 83 & $<0.001$ \\
\hline $\mathrm{N} 2 \mathrm{C}-\mathrm{N} 3$ & 82 & 67 & & 81 & 55 & & 82 & 81 & & 81 & 79 & \\
\hline \multicolumn{13}{|l|}{ Stage } \\
\hline$|-|||$ & 132 & 90 & 0.066 & 132 & 85 & 0.016 & 132 & 93 & 0.06 & 132 & 97 & 0.004 \\
\hline IVA-IVB & 454 & 79 & & 452 & 72 & & 454 & 86 & & 453 & 89 & \\
\hline \multicolumn{13}{|l|}{ Chemotherapy } \\
\hline Concurrent/no & 525 & 83 & $<0.001$ & 523 & 76 & 0.006 & 525 & 88 & 0.263 & 524 & 90 & 0.762 \\
\hline Induction & 61 & 71 & & 61 & 64 & & 61 & 83 & & 61 & 93 & \\
\hline \multicolumn{13}{|c|}{ Radiotherapy technique } \\
\hline 3D-CRT & 391 & 80 & 0.420 & 389 & 74 & 0.36 & 391 & 87 & 0.754 & 390 & 90 & 0.235 \\
\hline IMRT & 194 & 84 & & 194 & 76 & & 194 & 88 & & 194 & 92 & \\
\hline \multicolumn{13}{|l|}{ Treatment modality } \\
\hline CRT & 201 & 82 & 0.698 & 201 & 78 & 0.612 & 201 & 89 & 0.695 & 201 & 94 & 0.157 \\
\hline SRT & 385 & 81 & & 383 & 73 & & 385 & 87 & & 384 & 89 & \\
\hline
\end{tabular}

Abbreviations: OS overall survival, DFS disease-free survival, LRRFS locoregional recurrence-free survival, DMFS distant metastasis-free survival, ECOG Eastern Cooperative Oncology Group, PET/CT positron emission tomography-computed tomography, 3D-CRT three-dimensional conformal radiotherapy, IMRT intensity modulated radiotherapy, $C R T$ radiotherapy with chemotherapy, SRT surgery followed by radiotherapy

and DFS, but not for LRRFS or DMFS. Other prognostic factors such as old age, current smoking, poor initial performance status and advanced $\mathrm{T}$ stage were associated with inferior OS. For DFS, advanced N stage was an additional significant prognostic factor. However, in terms of LRRFS, patient age and use of induction chemotherapy were not included in the Cox model. Age, and $\mathrm{T}$ and $\mathrm{N}$ stage were also identified as independent prognostic factors for DMFS.

\section{Discussion}

Controversy surrounds the treatment of tonsil cancer. Both definitive surgery and radiotherapy resulted in favorable outcomes in retrospective studies [5-7]. With the use of chemotherapy, improved survival rates were reported with both treatment modalities $[9,10]$. However, no well-designed prospective study comparing radiotherapy and surgery has been completed in the era of widely used chemotherapy. The only prospective 

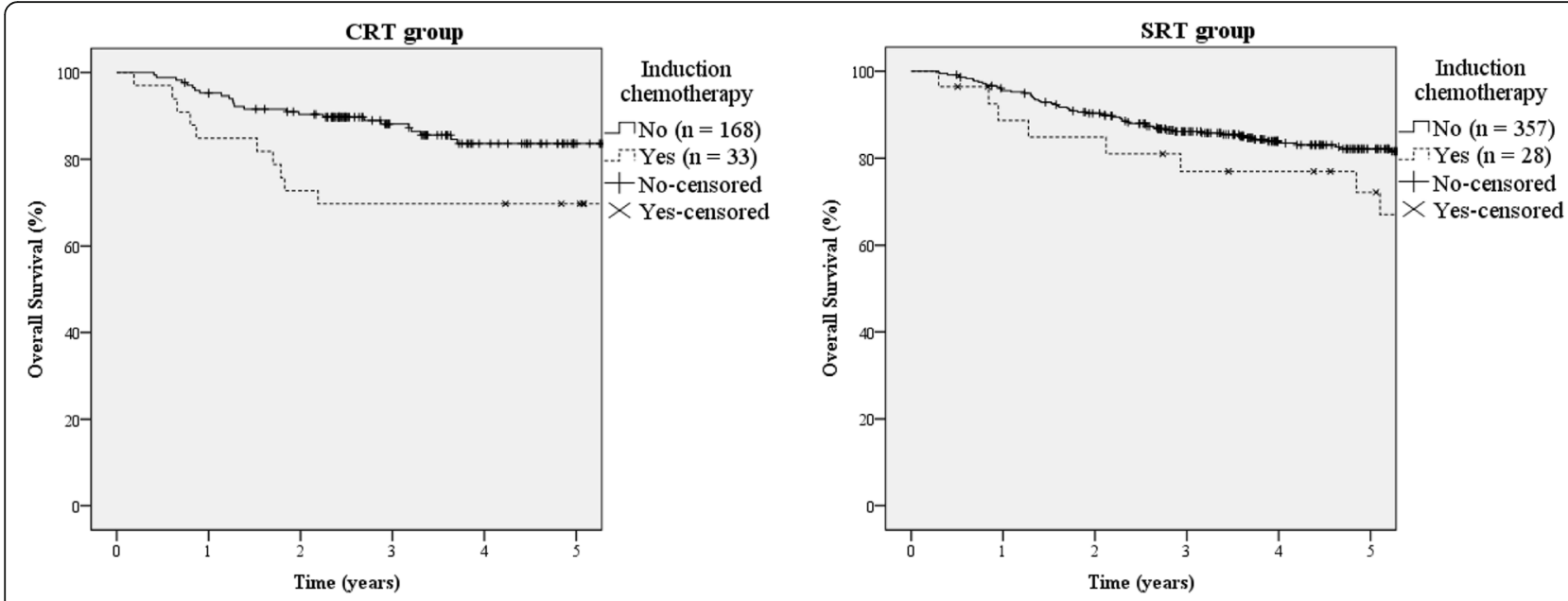

Fig. 2 Overall survival according to presence or absence of induction chemotherapy in each treatment group

randomized trial comparing chemoradiotherapy and surgery followed by radiotherapy was stopped prematurely due to slow accrual and therefore failed to detect any significant difference in DFS between treatment groups [13].

In the present study, we report the outcome of 586 patients from 16 hospitals. To the best of our knowledge, this is one of the largest tonsil cancer cohorts in the literature. We found that old age and advanced $\mathrm{T}$ stage which were associated with inferior survival in a multivariate analysis are more found in the CRT group. Despite these discrepancies in patient demographic and disease stage, there was no significant difference between the two treatment modalities under investigation in terms of survival, recurrence, or failure pattern. Our findings suggest that the CRT approach is more effective than SRT; however, further studies are required to confirm this hypothesis.

If the outcome is comparable between two treatment options, morbidity associated with the treatment becomes important when choosing the treatment modality. Unfortunately, we were unable to collect extensive information regarding treatment-related toxicities. Future trials should address not only the outcomes of treatment, but also any associated complications.

The outcomes of our multicenter study are comparable with those of previously published series. Canis et al. reported the outcome of 102 tonsil cancer patients

Table 3 Multivariate Analyses

\begin{tabular}{|c|c|c|c|c|c|c|c|c|c|c|c|c|}
\hline \multirow[b]{2}{*}{ Characteristics } & \multicolumn{3}{|l|}{ OS } & \multicolumn{3}{|l|}{ DFS } & \multicolumn{3}{|l|}{ LRRFS } & \multicolumn{3}{|l|}{ DMFS } \\
\hline & $p$-value & $\mathrm{HR}$ & $95 \% \mathrm{Cl}$ & $p$-value & $\mathrm{HR}$ & $95 \% \mathrm{Cl}$ & $p$-value & $\mathrm{HR}$ & $95 \% \mathrm{Cl}$ & $p$-value & $\mathrm{HR}$ & $95 \% \mathrm{Cl}$ \\
\hline \multicolumn{13}{|l|}{ Age (years) } \\
\hline$\geq 60$ & $<0.001$ & 3.000 & $2.001-4.497$ & $<0.001$ & 2.516 & $1.779-3.560$ & & & & 0.009 & 2.227 & $1.217-4.077$ \\
\hline \multicolumn{13}{|l|}{ Smoking history } \\
\hline Current smoker & 0.012 & 1.663 & $1.116-2.478$ & 0.015 & 1.54 & $1.089-2.176$ & 0.014 & 1.919 & $1.141-3.226$ & & & \\
\hline \multicolumn{13}{|l|}{ Performance status } \\
\hline ECOG 1-2 & 0.045 & 1.566 & $1.010-2.426$ & 0.017 & 1.587 & $1.087-2.315$ & 0.019 & 2.094 & $1.130-3.879$ & & & \\
\hline \multicolumn{13}{|l|}{ T stage } \\
\hline T3-T4 & $<0.001$ & 2.913 & $1.943-4.366$ & $<0.001$ & 2.572 & $1.808-3.659$ & 0.021 & 1.852 & $1.097-3.127$ & $<0.001$ & 3.312 & $1.804-6.082$ \\
\hline \multicolumn{13}{|l|}{ N stage } \\
\hline $\mathrm{N} 2 \mathrm{C}-\mathrm{N} 3$ & 0.069 & 1.542 & $0.966-2.462$ & 0.008 & 1.735 & $1.155-2.607$ & 0.075 & 1.747 & $0.946-3.226$ & 0.007 & 2.435 & $1.271-4.664$ \\
\hline \multicolumn{13}{|l|}{ Chemotherapy } \\
\hline Induction & 0.003 & 2.224 & $1.313-3.768$ & 0.033 & 1.712 & $1.044-2.806$ & & & & & & \\
\hline
\end{tabular}

Abbreviations: OS overall survival, DFS disease-free survival, LRRFS locoregional recurrence-free survival, DMFS distant metastasis-free survival, $H R$ hazard ratio, CI confidence interval, ECOG Eastern Cooperative Oncology Group 
who were treated with transoral laser microsurgery [14]. The 5-year locoregional control rates of $\mathrm{T} 1-\mathrm{T} 2$ and T3-T4 stage tumors were 78 and $75 \%$, respectively. In the current study, the corresponding rates were 90 and $81 \%$, respectively. Similarly, researchers from MD Anderson Cancer Center reported 5-year locoregional control and OS rates of 97 and 86\%, respectively, in 120 patients who were treated with tonsillectomy followed by postoperative radiotherapy [15]. Poulsen et al. studied the outcomes of 148 patients who received surgery followed by radiotherapy or definitive radiotherapy [16], yielding 5-year locoregional control and OS rates of 84 and $57 \%$, respectively. Other studies performed before the early 2000s reported lower 5-year locoregional control rates of $63-77 \%$ and OS rates of $53-60 \%[7,17-19]$, possibly because these studies included a large proportion of patients who were treated in the pre-chemotherapy era. Although direct comparisons are not possible, our treatment outcomes are acceptable when compared with the literature.

In the present study, the induction chemotherapy approach negatively influenced both OS and DFS, but had little effect on LRRFS or DMFS in the multivariate analysis. These findings suggest that induction chemotherapy may cause non-cancer related death. Recently, randomized trials reported increased toxicities and no survival gain with induction chemotherapy $[20,21]$. Despite the limitations of retrospective studies (e.g., patient selection), our findings support the proposal that the toxicity associated with routine use of induction chemotherapy might be potentially harmful to tonsil cancer patients who are highly curable without such treatment. This is further indicated by our finding that patients with tonsil cancer showed favorable prognosis and a low rate of distant metastasis, despite $86 \%$ demonstrating stage III-IVA disease.

Tobacco smoking is a well-known risk factor for head and neck cancer [22]. Indian researchers reported that prior tobacco abuse was an independent poor prognostic factor for DFS and locoregional control in oropharyngeal cancer [23]. Less than half of tumors in that study were located in the tonsils. In our study, current smokers showed significantly worse OS, DFS, and LRRFS than non- or ex-smokers in the multivariate analysis. Differing tumor biology in smokers may affect disease outcome [24]. It is well known that persistent smoking during radiation therapy adversely affects the response and survival rate of head and neck cancer patients [25]. Smoking cessation may be beneficial and should be encouraged in patients with tonsil cancer.

Age of $>60$ years was associated with a significant risk of death, disease recurrence, and distant metastasis in the multivariate analysis. HPV infection, which correlated with favorable prognosis, was more frequently observed in younger patients than in the elderly; [12] therefore, smoking history and old age could be secondary surrogates of poor tumor biology which is unrelated to HPV infection. Unfortunately, because the HPV status of patients in the present study was unknown, this hypothesis could not be tested. Regarding that many recent studies for altering therapy based on HPV status are in progress, the lack of details of HPV status in this study has significant limitations [26].

\section{Conclusion}

Our large, multicenter, retrospective review of tonsil cancer patients showed favorable survival and disease control. Despite more high-risk patients being treated with definitive chemoradiotherapy than surgery followed by radiotherapy, demonstrated comparable outcomes. Furthermore, our study indicated that induction chemotherapy is correlated with significant risk of death and should not be routinely given to tonsil cancer patients.

\section{Additional file}

Additional file 1: Ethics information. (DOCX $13 \mathrm{~kb}$ )

\section{Abbreviations}

CRT: Chemoradiotherapy; CT: Computed tomography; DFS: Disease-free survival; DMFS: Distant metastasis-free survival; ECOG: Eastern Cooperative Oncology Group; HPV: Human papillomavirus; IMRT: Intensity modulated radiotherapy; KROG: Korean Radiation Oncology Group; LRRFS: Locoregional recurrence-free survival; OS: Overall survival; PET: Positron emission tomography; SRT: Surgery followed by postoperative radiotherapy

\section{Acknowledgements}

None.

\section{Funding}

This research was supported by a grant from the National Research Foundation of Korea (NRF), which is funded by the Korean government (MEST, grant no.2015M2A2A7055063); a grant of the Korean Health Technology R\&D Project, Ministry of Health and Welfare, Republic of Korea (H14C3459); and the National R\&D Program through the Dong-nam Institute of Radiological and Medical Sciences (DIRAMS) funded by the Ministry of Education, Science, and Technology (50595-2016). The funding bodies had no role in the design of the study and collection, analysis, and interpretation of data and in writing the manuscript.

\section{Availability of data and materials}

The datasets generated during and/or analysed during the current study are available from the corresponding author on request.

\section{Authors' contributions}

SS, HGW, LCG, KCK, YCA, DO, SWL, KHC, YSK, YTO and WTK were involved in the study concept and design. Data acquisition was undertaken by $C G L, K C K$, MSK, DO, HJP, SWL, GP, SHM, YW, YTO, WTK and JUJ. Analysis and interpretation of data were performed by SS, HGW, YCA, YSK and KHC. SS, HGW, HJP, GP, MSK, SHM, YW and JUJ drafted the manuscript. All of the authors have read and approved the final manuscript.

\section{Ethics approval and consent to participate}

The study protocol was reviewed and approved by the Institutional Review Boards of all participating hospitals, and adhered to the tenets of the Declaration of Helsinki. Owing to retrospective approach of this study, the need for informed consent was waived by the ethics committees. Additional information about the ethics committees and waiver of informed consent is provided in Additional file 1. 


\section{Consent for publication}

Not applicable.

\section{Competing interests}

The authors declare that they have no competing interests.

\section{Publisher's Note}

Springer Nature remains neutral with regard to jurisdictional claims in published maps and institutional affiliations.

\section{Author details}

'Department of Radiation Oncology, Kangwon National University Hospital, Baengnyeong-ro 156, Chuncheon 24289, Republic of Korea. ${ }^{2}$ Department of Radiation Oncology, Seoul National University College of Medicine, 101 Daehangno, Jongno-gu, Seoul 110-744, Republic of Korea. ${ }^{3}$ Department of Radiation Oncology, Yonsei Cancer Center, 50-1 Yonsei-ro, Seodaemun-gu, Seoul 03722, Republic of Korea. ${ }^{4}$ Department of Radiation Oncology, Samsung Medical Center, Sungkyunkwan University School of Medicine, 81 Irwon-Ro Gangnam-gu, Seoul 06351, Republic of Korea. ${ }^{5}$ Department of Radiation Oncology, Asan Medical Center, University of Ulsan College of Medicine, Seoul, South Korea. ${ }^{6}$ Research Institute and Hospital, National Cancer Center, 323 Ilsan-ro, Ilsandong-gu, Goyang-si, Gyeonggi-do 10408, Republic of Korea. ${ }^{7}$ Department of Radiation Oncology, Seoul St. Mary's Hospital, The Catholic University of Korea, 222 Banpo-daero, Seocho-gu Seoul 06591, Republic of Korea. ${ }^{8}$ Department of Radiation Oncology, Ajou University School of Medicine, Gyeonggi, South Korea. ${ }^{9}$ Department of Radiation Oncology, Pusan National University Hospital and Pusan National University School of Medicine, 179 Gudeok-ro, Seo-gu, Busan 49241, Republic of Korea. ${ }^{10}$ Department of Radiation Oncology, Chonnam National University Medical School, 42 Jebong-ro, Dong-gu, Gwangju 61469, Republic of Korea.

Received: 28 July 2016 Accepted: 21 August 2017

Published online: 30 August 2017

\section{References}

1. Cohan DM, Popat S, Kaplan SE, Rigual N, Loree T, Hicks WL Jr. Oropharyngeal cancer: current understanding and management. Curr Opin Otolaryngol Head Neck Surg. 2009;17:88-94.

2. Olaleye O, Moorthy R, Lyne O, Black M, Mitchell D, Wiseberg J. A 20-year retrospective study of tonsil cancer incidence and survival trends in South East England: 1987-2006. Clin Otolaryngol. 2011;36:325-35.

3. Mehta V, Yu GP, Schantz SP. Population-based analysis of oral and oropharyngeal carcinoma: changing trends of histopathologic differentiation, survival and patient demographics. Laryngoscope. 2010;120:2203-12.

4. Chung EJ, Oh JI, Choi KY, et al. Pattern of cervical lymph node metastasis in tonsil cancer: predictive factor analysis of contralateral and retropharyngeal lymph node metastasis. Oral Oncol. 2011;47:758-62.

5. Park G, Lee SW, Kim SY, et al. Can concurrent chemoradiotherapy replace surgery and postoperative radiation for locally advanced stage III/IV tonsillar squamous cell carcinoma? Anticancer Res. 2013;33:1237-43.

6. Koo TR, Wu HG, Hah JH, et al. Definitive radiotherapy versus postoperative radiotherapy for tonsil cancer. Cancer Res Treat. 2012;44:227-34.

7. Mendenhall WM, Amdur RJ, Stringer SP, Villaret DB, Cassisi NJ. Radiation therapy for squamous cell carcinoma of the tonsillar region: a preferred alternative to surgery? J Clin Oncol. 2000;18:2219-25.

8. NCCN Guidelines Panels. NCCN clinical practice guidelines in oncology: head and neck cancers. Available from URL: https://www.nccn.org/ professionals/physician_gls/pdf/head-and-neck.pdf. Accessed 29 Aug 2017.

9. Calais $\mathrm{G}$, Alfonsi $\mathrm{M}$, Bardet $\mathrm{E}$, et al. Randomized trial of radiation therapy versus concomitant chemotherapy and radiation therapy for advancedstage oropharynx carcinoma. J Natl Cancer Inst. 1999;91:2081-6.

10. Cooper JS, Pajak TF, Forastiere AA, et al. Postoperative concurrent radiotherapy and chemotherapy for high-risk squamous-cell carcinoma of the head and neck. N Engl J Med. 2004;350:1937-44.

11. Ang KK, Harris J, Wheeler R, et al. Human papillomavirus and survival of patients with oropharyngeal cancer. N Engl J Med. 2010;363:24-35.

12. Westra $\mathbf{W H}$. The changing face of head and neck cancer in the 21 st century: the impact of HPV on the epidemiology and pathology of oral cancer. Head Neck Pathol. 2009;3:78-81.
13. Soo KC, Tan EH, Wee J, et al. Surgery and adjuvant radiotherapy vs concurrent chemoradiotherapy in stage III/IV nonmetastatic squamous cell head and neck cancer: a randomised comparison. Br J Cancer. 2005;93:279-86.

14. Canis M, Martin A, Kron M, et al. Results of transoral laser microsurgery in 102 patients with squamous cell carcinoma of the tonsil. Eur Arch Otorhinolaryngol. 2013;270:2299-306.

15. Yildirim G, Morrison WH, Rosenthal Dl, et al. Outcomes of patients with tonsillar carcinoma treated with post-tonsillectomy radiation therapy. Head Neck. 2010;32:473-80.

16. Poulsen M, Porceddu SV, Kingsley PA, Tripcony L, Coman W. Locally advanced tonsillar squamous cell carcinoma: treatment approach revisited. Laryngoscope. 2007;117:45-50.

17. Mendenhall WM, Morris CG, Amdur RJ, et al. Definitive radiotherapy for tonsillar squamous cell carcinoma. Am J Clin Oncol. 2006;29:290-7.

18. Pernot M, Malissard L, Hoffstetter S, et al. Influence of tumoral, radiobiological, and general factors on local-control and survival of a series of 361 tumors of the velotonsillar area treated by exclusive irradiation (external-beam irradiation plus brachytherapy or brachytherapy alone). Int J Radiat Oncol Biol Phys. 1994;30:1051-7.

19. Perez CA, Patel MM, Chao KSC, et al. Carcinoma of the tonsillar fossa: prognostic factors and long-term therapy outcome. Int J Radiat Oncol BiolPhys. 1998:42:1077-84.

20. Haddad R, O'Neill A, Rabinowits G, et al. Induction chemotherapy followed by concurrent chemoradiotherapy (sequential chemoradiotherapy) versus concurrent chemoradiotherapy alone in locally advanced head and neck cancer (PARADIGM): a randomised phase 3 trial. Lancet Oncol. 2013;14:257-64.

21. Cohen EEW, Karrison T, Kocherginsky M, et al. DeCIDE: a phase III randomized trial of docetaxel (D), cisplatin (P), 5-fluorouracil (F) (TPF) induction chemotherapy (IC) in patients with N2/N3 locally advanced squamous cell carcinoma of the head and neck (SCCHN). ASCO Meeting Abstracts. 2012;30: 5500

22. Marur S, Forastiere AA. Head and neck cancer: changing epidemiology, diagnosis, and treatment. Mayo Clin Proc. 2008:83:489-501.

23. Agarwal JP, Mallick I, Bhutani $R$, et al. Prognostic factors in oropharyngeal cancer-analysis of 627 cases receiving definitive radiotherapy. Acta Oncol. 2009;48:1026-33.

24. Ragin CC, Taioli E, Weissfeld JL, et al. 11q13 amplification status and human papillomavirus in relation to p16 expression defines two distinct etiologies of head and neck tumours. Br J Cancer. 2006:95:1432-8.

25. Browman GP, Wong G, Hodson I, et al. Influence of cigarette smoking on the efficacy of radiation therapy in head and neck cancer. N Engl J Med. 1993;328(3):159-63.

26. Vokes EE, Agrawal N, Seiwert TY. HPV-associated head and neck cancer. J Natl Cancer Inst. 2015;107(12):djv344.

\section{Submit your next manuscript to BioMed Central and we will help you at every step:}

- We accept pre-submission inquiries

- Our selector tool helps you to find the most relevant journal

- We provide round the clock customer support

- Convenient online submission

- Thorough peer review

- Inclusion in PubMed and all major indexing services

- Maximum visibility for your research

Submit your manuscript at www.biomedcentral.com/submit
) Biomed Central 